\title{
On the Wildside 2: the natural history of Glasgow Botanic Gardens revisited
}

\author{
J.R. Downie ${ }^{1} \&$ S.J. Forster ${ }^{2}$ \\ ${ }^{1}$ School of Life Sciences, Graham Kerr Building, University of Glasgow, Glasgow G12 8QQ \\ ${ }^{2}$ RSPB South West Scotland Regional Office, 10 Park Quadrant, Glasgow G3 6BS \\ ${ }^{1}$ E-mail: roger.downie@glasgow.ac.uk
}

\section{INTRODUCTION}

In 1998 and 1999, The Glasgow Naturalist (TGN) published a set of papers under the heading "On the Wildside: the Natural History of the Glasgow Botanic Gardens", which reported the results of wildlife surveys carried out over the previous four years in the Glasgow Botanic Gardens. Table 1 lists the topics covered. As the year of the Botanic Gardens' bicentenary (2017) approached, Glasgow Natural History Society (GNHS) members felt that this could provide a good motivation for a new look at the biodiversity (in the wild state) of the Gardens. After discussions with staff of the Royal Society for the Protection of Birds' (RSPB) "Giving Nature a Home" project in Glasgow, it was decided that the new survey would be in two parts. First, a collation of new records made since the last surveys, a period of about 20 years. Second, the results of a BioBlitz in the Gardens, which would launch the RSPB's city wide "Wildfest 2017".

The concept of a BioBlitz was developed by Sam Droege and Dan Roddy in Washington DC in 1996, with the name actually coined by Susan Rudy (Wikipedia). A BioBlitz is intended to be an enjoyable and exciting event, usually over a period of one or two days (hence the "blitz" part of the name: something short and intense), bringing together non-university-based naturalists, university-based scientists, and volunteers in a race against time to survey all possible forms of life in an area of green space. It is intended to be a way of breaking down barriers to engagement with science, and raising awareness of the importance of biological recording. It provides an opportunity for members of the public to contribute to science, as part of the more general idea of "Citizen Science" and highlights the fact that you do not need to be an expert to make a contribution, though the experts can help.

The following papers provide the first set of results of both the long-term recording and the Blitz approach. Most of the articles both report on what new has been found and reflect on changes since the earlier surveys, where this information is available.

As was the case for the results in the 1990s, collating and writing up all the recent findings has taken longer than initially anticipated. Rather than wait until all the expected papers had been received, we decided to publish in two batches, six papers in this $T G N$ issue, the remainder in the next one. We hope that this set of articles by Sarah-Jayne Forster, Richard Sutcliffe, Roy Watling and Richard Weddle will whet your appetites for the rest. It is worth noting here that the new set of papers does not give only an update on what came before. For example, the fungi of the gardens were not covered in the previous set of papers, and Roy Watling's article gives a valuable historical account of fungi recorded in the Gardens, both at the earlier Sandyford site and at Kelvinside.

In editing the 1998-99 account, Geoff Hancock indicated that the papers, when completed, would be assembled into a booklet. Unfortunately, this never happened, but the subsequent arrival of the internet may render such separate publication redundant. Past papers in $T G N$ are now available online with open access at the Biodiversity Heritage Library (www.biodiversitylibrary.org/ ), and new papers appear on the GNHS website as they are published, and so are accessible to all.

\begin{tabular}{ll}
\hline Title & Author(s) \\
\hline Introduction & G. Hancock (overall editor) \\
An historical introduction & E. Curtis \\
Plants growing in a wild state & P. Macpherson \\
Trees of Glasgow Botanic Gardens & R. Gray \\
Birds for all seasons & N. Grist \& I. McCallum \\
Resident wildlife, seen and unseen: mammals & R. Sutcliffe \\
Underneath it all: the geology of the Botanic Gardens area & B. Skillen \\
Hidden wildlife: the resident population of invertebrates & G. Hancock \\
\hline
\end{tabular}

Table 1. Papers included in "On the Wildside", The Glasgow Naturalist 23(3,4). 